\title{
The use of and satisfaction with prosthesis and quality of life in patients with combat related lower limb amputation, experience of a tertiary referral amputee clinic in Turkey
}

\author{
Yasin Demir ${ }^{1}$, N.Merve Örücü Atar ${ }^{1}$, Ümüt Güzelküçük ${ }^{1-2}$, Koray Aydemir ${ }^{1-2}$, Evren Yaşar ${ }^{1-2}$ \\ (1) Gaziler Physical Medicine and Rehabilitation Training and Research Hospital, Ankara, Turkey \\ (2) University of Health Sciences, Gülhane Faculty of Medicine, Department of Physical Medicine and Rehabilitation, \\ Ankara, Turkey
}

Date submitted:

Oct 10, 2018

Date accepted:

July 30, 2018

Online publication date:

March 15, 2019

\section{Corresponding Author: \\ Yasin Demir \\ Gaziler Physical Medicine and \\ Rehabilitation Training and \\ Research Hospital, Ankara, \\ Turkey \\ yasin.demir3@saglik.gov.tr}

Keywords: amputation, prosthesis, quality of life.

\begin{abstract}
Aims:The aim of current study was to evaluate the prosthesis use, level of satisfaction, reported problems and quality of life in patients with combat related lower limb amputation.

Methods:In this descriptive study, a total of 30 patients with 35 amputations were included. The survey collected data on basic demographics including age, time since amputation, gender, etiology, level and side of the amputation, daily prosthetic use frequency, daily total prosthetic wearing time, satisfaction with prosthesis, causes of dissatisfaction and any problems related to the amputation. Satisfaction with the prosthetic device was measured with a numeric scale (0 to 10).Quality of life was assessed with Short-Form Health Survey (SF-36).
\end{abstract}

Results:The leading reasons for rejection or dissatisfaction with the lower limb prosthesis were excessive perspiration, itching and pain. The mean daily prosthesis wearing time was $11.4 \pm 3.8$ hours. There was a negative correlation between daily prosthesis wearing time and cosmetic anxiety $(r:-0.416)(p<0.05)$. The mean satisfaction level with prosthesis was $7 \pm 3.8$ and itching, pain and wound were significantly correlated with satisfaction level ( $r:-0.491,-0.528$ and -0.480 , with respectively) $(p<0.05)$. SF-36 scores were found to be lower for amputees when compared to those for the general population in Turkey.

Conclusions:Participants reported high levels of use and satisfaction with prosthesis, in spite of excessive perspiration, itching and pain. Future efforts should aim to improve prostheticdevice design and quality of life for patients with combat related lower limb amputation.

\section{Introduction}

The incidence of acquired amputations differs from 1.2 to 4.4 per $10.000(1,2)$ and it is estimated that it will probably reach to a total of 3.6 million by the year 2050 (3). In developed countries, peripheral vascular disease accounted for $80-90 \%$ of all amputations, and traumatic accident rates have either been constant or declining (4-6). On the other hand, in developing countries, trauma is the main cause of amputation, and in countries where landmines exist, they also lead to increased rate of amputation $(7,8)$.

As compared to the upper limb amputees, the lower limb amputees experience more changes in their life after the amputation and this situation may result in considerable morbidity for an individual, especially in mobility (9). A traumatic lower limb amputation (LLA) is commonly seen in young, active people and not only it can be devastating but also functional capacity and quality of life can often be limited during the patient's most productive years (10).

Prosthetic technology has been developing especially in last decade and the goal of prosthetic rehabilitation is to maximize function and quality of life (11). Ambulation pattern, socket comfort and safety are greater in new prosthesis. However, some individuals with LLA encounter problems during use of prosthesis in terms of satisfaction and health quality, which may result in rejection or abandonment of the device.

The prosthetic experience of combat-injured patients has received little attention in the current literature. The purpose of current study was to evaluate the frequency of prosthesis use, the level of satisfaction and quality of life in patients with traumatic LLA and to determine which factors led to rejection of the prosthesis. Thus, it is hoped that the results of the study will guide future research and development efforts of lower limb prostheses.

\section{Methods}

This study was planned as a prospective study. A total of 56 patients were referred to the authors' department, which is a tertiary prosthetic rehabilitation center in Turkey, for the fitting of a prosthesis following traumatic amputation of the lower limb. Of the total 56, 10 patients had toe(s) amputation, 9 patients had non-traumatic LLA, and 7 patients could not be traced. 
Thus, 30 amputees were included in the study. Approval for the study was granted by the Ethics Committee of Ankara Numune Education and Research Hospital and it was conducted in accordance with the Helsinki Declaration 2008 principles. All patients signed informed consent.

In this survey, data on basic demographics including age, time since amputation, gender, etiology, level and side of the amputation, daily prosthetic use frequency, daily total prosthetic wearing duration, satisfaction with prosthesis, causes of dissatisfaction and any problems related to the amputation were collected. The lower extremity prosthetic type was also recorded. A sample of prosthesis could be seen in figure 1 .

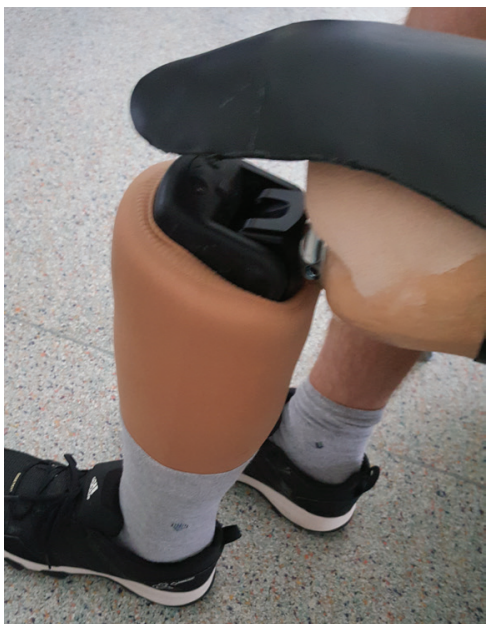

Daily duration of prosthesis wearing time was evaluated with a 4-point Likert scale: (0) never, (1) rarely, (2) at work, (3) all day. In addition, patients were asked "How many hours do you use your lower extremity prosthesis in a day?" The level satisfaction with the prosthetic device was measured with a numeric scale. Patients were asked to give a number between 0 and 10 , which 0 means dissatisfied, 10 means completely satisfied. Perceived problems with the prosthesis were assessed with a seven item problem scale, consisting of items referring to heaviness, excessive perspiration, itching, cosmetic anxiety, pain, wound, poor socket fit or suspension.

Health related quality of life was assessed by Short-Form Health Survey (SF-36). The SF-36 is a generic questionnaire that can be used for the general population and in different patient groups. It has been validated in the Turkish population (12). The SF-36 consists of 36 questions integrating eight multi item scales: physical functioning; role limitations caused by physical problems; bodily pain; general health perceptions; vitality, energy, or fatigue; social functioning; role limitations caused by emotional problems, and general mental health. It also provides two summary scales: Physical Component Summary and Mental Component Summary. Scores on each of the sub-scales range from 0 to 100 , with 0 representing the worst health-related quality of life and 100 representing the best.

Statistical analysis was performed using SPSS v.15.0 for Windows software (SPSS, Chicago, IL, USA). Continuous variables are expressed as means or medians with standard deviations or minimum-maximum values. Categorical variables are presented as percentage frequencies. The Kolmogorov-Smirnov test was used to confirm that the data were within the ranges of normal distribution. We used Student's t-test and Pearson test for normally distributed data or Mann Whitney $U$ and Spearman tests for data that were not normally distributed. We used $x 2$ test or Fisher's exact test to compare categorical data. Correlation coefficients whose magnitude were between 0.9 and 1.0 indicated variables which could be considered very highly correlated. Correlation coefficients whose magnitude were between 0.7 and 0.9 indicated variables which could be considered highly correlated. Correlation coefficients whose magnitude were between 0.5 and 0.7 indicated variables which could be considered moderately correlated. Correlation coefficients whose magnitude were between 0.3 and 0.5 indicated variables which have a low correlation. A p-value of 0.05 or less was chosen to reflect statistical significance.

\section{Results}

The mean age at the time of amputation was $23.3 \pm 3.73$ years. The mean time since amputation was $12.9 \pm 7.1$ years. All of the patients were male. The leading reason for combat related LLA was mine related injuries (22 patients, $73.3 \%$ ). The leading level of amputation was below knee (18 patients). The most commonly used lower limb prostheses were active vacuum system modular prosthesis and microprocessor controlled knee prosthesis. The demographic and clinical features of the patients are summarized in Table 1.

\begin{tabular}{|c|c|}
\hline & Patients \\
\hline Age (years) & $36.0 \pm 7.1$ \\
\hline Age at time of amputation (years) & $23.3 \pm 3.73$ \\
\hline Time since amputation (years) & $12.9 \pm 7.01$ \\
\hline $\begin{array}{l}\text { The mean daily prosthetic wearing time } \\
\text { (hours) }\end{array}$ & $11.4 \pm 3.8$ \\
\hline $\begin{array}{l}\text { Side }(\mathrm{n}: 35) \\
\text { Right } \\
\text { Left } \\
\text { Bilateral }\end{array}$ & $\begin{array}{c}16(53.3) \\
9(30) \\
5(16.7)\end{array}$ \\
\hline $\begin{array}{l}\text { Level of amputation }(\mathrm{n}: 35) \\
\text { Above knee } \\
\text { Knee disarticulation } \\
\text { Below knee } \\
\text { Syme } \\
\text { Chopart }\end{array}$ & $\begin{array}{c}9(25.7) \\
2(5.7) \\
18(51.4) \\
5(14.2) \\
1(2.8)\end{array}$ \\
\hline $\begin{array}{l}\text { Type of prosthesis ( } \mathrm{n}: 35 \text { ) } \\
\text { Microprocessor-controlled knee pros- } \\
\text { thesis } \\
\text { Active vacuum system modular pros- } \\
\text { thesis } \\
\text { Syme prosthesis } \\
\text { Partial foot prosthesis }\end{array}$ & $\begin{array}{c}11(2.3) \\
18(51.4) \\
5(14.2) \\
1(2.8)\end{array}$ \\
\hline
\end{tabular}

The most common reported problem in lower limb prosthesis user patients was excessive perspiration (18 patients, 60\%). Itching related with prosthetic use was reported by $14(46.7 \%)$ patients. Other faced problems were: pain (12 patients, $40 \%)$, wound (11 patients, $36.7 \%$ ), poor socket fit or suspension ( 8 patients, $26.7 \%$ ) heaviness of the prosthesis (6 patients, $20 \%$ ), and cosmetic anxiety (2 patients, $6.7 \%$ )

At the time of the study, all lower limb amputees were using their prosthesis. Nineteen $(63.3 \%)$ patients were using the prosthesis all day, $9(30 \%)$ patients were using frequently and $2(6.7 \%)$ patients were using rarely and none of the amputees had rejected prosthesis use. The mean daily prosthetic wearing time was $11.4 \pm 3.8$ hours. There was no significant difference for the daily prosthesis wearing time between patients with above knee (included knee disarticulation) and other levels $(11.9 \pm 3.9$ vs. $11.2 \pm 3.9)(p>0.05)$. In addition, there was no sig- 
nificant difference for the daily prosthesis using time between patients with bilateral and unilateral amputations $(12.2 \pm 3.3$ vs. $11.2 \pm 4.1)(p>0.05)$. There was a statistically significant low correlation between the daily prosthesis using time and the cosmetic anxiety ( $r:-0.416)(p<0.05)$. The mean daily prosthesis using time was $5.5 \pm 6.3$ hours in patients with cosmetic anxiety and $11.8 \pm 3.4$ hours in patients without cosmetic anxiety.

The mean satisfaction level with prosthesis was $7 \pm 3.8$ in patients with LLA. Seven patients (23.3\%) give 10 point as satisfaction level on a 10-point rating scale. Only $2(6.7 \%)$ patients gave 2 point on the scale as lowest score. The mean level of satisfaction with prosthesis of patients with above knee (included knee disarticulation) and other levels were so close $(7 \pm 2.3$ vs. $7 \pm 3.5)(p>0.05)$. There was no significant difference for the satisfaction level between patients with bilateral and unilateral amputations $(8.4 \pm 1.1$ vs. $6.7 \pm 3.3)(p>0.05)$. There was a statistically significant moderate correlation between the satisfaction level and pain $(r:-0.528)(p<0.05)$. There were low correlations between the satisfaction level and itching and wound ( $r:-0.491$, and -0.480 , with respectively) $(p<0.05)$.

The mean SF-36 subscale scores were physical functioning $69.1 \pm 22.6$, physical role $50.5 \pm 41.3$, bodily pain $55.1 \pm 31.9$, general health $57.1 \pm 22.0$, vitality $53.7 \pm 22.9$, social functioning 56.2 \pm 27.9 , emotional role $58.8 \pm 39.8$, and mental health 55.7 \pm 23.6 . All mean SF-36 subscale scores were lower than the Turkish population norm values (13) (Table 2). Patient reported problems were analyzed for correlation with SF-36 scores. Seating was correlated with physical $(r$ : -0.478$)$ and emotional role $(r:-0.563)(p<0.05)$. The highest correlation was found between pain and physical functioning ( $r$ : -0.612). Other statistically significant correlations were: itching with physical functioning ( $\mathrm{r}:-0.532)$ (moderate) and social functioning (r: -0.390$)($ low), pain with bodily pain $(r:-0.367)($ low $)$, general health (r:-0.518)(moderate), vitality (r:-0.473)(low), social functioning ( $r$ :-0.493)(low) and emotional role ( $r$ : -0.534$)$ (moderate), wound with physical functioning ( $r:-0.514)$ (moderate), physical role $(r:-0.498)(l o w)$, general health $(r:-0.386)(l o w)$, vitality ( $r$ :$0.368)($ low $)$ and social functioning (r:-0.396)(low), poor socket fit or suspension with physical role (r:-0.471)(low) and emotional role (r: -0.441)(low) (Table 3).

\begin{tabular}{|c|c|c|}
\hline & Total & Turkish population* \\
\hline Physical functioning & $69.1 \pm 22.6$ & $87.2 \pm 17.1$ \\
\hline Physical role & $50.5 \pm 41.3$ & $89.8 \pm 19.3$ \\
\hline Bodily pain & $55.1 \pm 31.9$ & $85.1 \pm 16.4$ \\
\hline General health & $57.1 \pm 22.0$ & $73.6 \pm 14.9$ \\
\hline Vitality & $53.7 \pm 22.9$ & $65.7 \pm 11.9$ \\
\hline Social functioning & $56.2 \pm 27.9$ & $91.7 \pm 12.8$ \\
\hline Emotional role & $58.8 \pm 39.8$ & $92.8 \pm 15.1$ \\
\hline Mental health & $55.7 \pm 23.6$ & $71.0 \pm 10.6$ \\
\hline
\end{tabular}

\section{Discussion}

In this study, it was aimed to evaluate daily prosthetic use, satisfaction rates and quality of life and to determine the reasons for non-use and dissatisfaction of the prosthesis in patients with combat related LLA. The leading reason of war related LLA was mine related injury and most common amputation level was below the knee. The results have shown that daily prosthetic use and satisfaction rate were high. The leading reasons for rejection or dissatisfaction with the lower limb prosthesis were excessive perspiration, itching and pain. Cosmetic anxiety was significantly correlated with daily prosthesis wearing time. Itching, pain and wound were significantly correlated with satisfaction with prosthesis. This study also revealed a lower quality of life when compared with the general age adjusted Turkish population.

Patient reported problems could be useful and helpful for developing new prosthesis. Van de Weg et al. reported excessive perspiration, pain and skin disorders as leading causes of dis-

Table 3. Relationship between SF-36 scores and patient reported problems

\begin{tabular}{|c|c|c|c|c|c|c|c|c|}
\hline & & Sweating & Itching & Pain & Wound & $\begin{array}{c}\text { Poor socket fit or } \\
\text { suspension }\end{array}$ & Heaviness & $\begin{array}{c}\text { Cosmetic } \\
\text { anxiety }\end{array}$ \\
\hline \multirow{2}{*}{$\begin{array}{l}\text { Physical } \\
\text { functioning }\end{array}$} & r: & -0.277 & $-0.532^{*}$ & $-0.612^{*}$ & $-0.514^{*}$ & -0.245 & -0.208 & 0.016 \\
\hline & p: & 0.139 & 0.003 & 0.001 & 0.004 & 0.192 & 0.270 & 0.935 \\
\hline \multirow{2}{*}{ Physical role } & r: & $-0.478^{*}$ & -0.402 & $-0.579^{*}$ & $-0.498^{*}$ & $-0.471^{*}$ & -0.228 & -0.008 \\
\hline & $\mathrm{p}:$ & 0.008 & 0.028 & 0.001 & 0.005 & 0.009 & 0.225 & 0.967 \\
\hline \multirow{2}{*}{ Bodily pain } & r: & -0.221 & -0.190 & $-0.367^{*}$ & -0.245 & 0.101 & -0.082 & 0.357 \\
\hline & p: & 0.241 & 0.315 & 0.046 & 0.192 & 0.597 & 0.666 & 0.053 \\
\hline \multirow{2}{*}{$\begin{array}{l}\text { General } \\
\text { health }\end{array}$} & r: & -0.028 & -0.350 & $-0.518^{*}$ & $-0.386^{*}$ & -0.250 & -0.058 & 0.016 \\
\hline & $\mathrm{p}:$ & 0.885 & 0.058 & 0.003 & 0.035 & 0.183 & 0.760 & 0.935 \\
\hline \multirow{2}{*}{ Vitality } & $\mathrm{r}:$ & -0.024 & -0.325 & $-0.473^{*}$ & $-0.368^{*}$ & -0.292 & 0.058 & -0.101 \\
\hline & p: & 0.901 & 0.080 & 0.008 & 0.045 & 0.117 & 0.761 & 0.597 \\
\hline \multirow{2}{*}{$\begin{array}{l}\text { Social } \\
\text { functioning }\end{array}$} & $\mathrm{r}:$ & 0.028 & $-0.390^{*}$ & $-0.493^{*}$ & $-0.396^{*}$ & -0.313 & -0.097 & -0.031 \\
\hline & p: & 0.884 & 0.033 & 0.006 & 0.030 & 0.093 & 0.609 & 0.870 \\
\hline \multirow{2}{*}{ Emotional role } & r: & $-0.563^{*}$ & -0.323 & $-0.534^{*}$ & -0.267 & $-0.441^{*}$ & -0.302 & 0.065 \\
\hline & p: & 0.001 & 0.082 & 0.002 & 0.154 & 0.015 & 0.105 & 0.735 \\
\hline \multirow{2}{*}{ Mental health } & $\mathrm{r}:$ & -0.063 & -0.349 & -0.430 & -0.329 & -.0236 & -0.097 & -0.186 \\
\hline & p: & 0.740 & 0.059 & 0.018 & 0.076 & 0.209 & 0.611 & 0.325 \\
\hline
\end{tabular}


comfort, especially in users of socket with polyethylene foam (14). Skin irritation and wound were reported by one-fourth of the patients related with prosthetic use in another study (15). Similarly, Pezzin et al. reported phantom pain, wounds, or sores as faced issues during prosthesis use (16). With parallel to current literature, combat related lower limb amputees reported excessive perspiration and pain as leading cause of discomfort in current study. However, itching was more commonly reported in this study when compared to the previous studies. It could be concluded that the material used to fabricate prosthetic sockets may have led to itching. This issue should be taken into consideration when designing new socket systems.

Pezzin et al. investigated prosthesis use in patients with LLA and found that the mean prosthesis use was 71 hours per week, in other words, the prosthetic device was used for approximately 10 hours in a day (9). Similarly, Dillingham et al. reported mean prosthesis wearing time as nearly 11 hours in a day (15). It has been reported that $84 \%$ of the lower limb amputees injured in Vietnam and $94 \%$ of the patients injured in Iraqi have been using their prosthesis regularly (17). The mean daily prosthesis wearing time was 11.4 hours in the current study and this is, to the best of our knowledge, the highest daily prosthetic wearing duration in patients with amputations. New prosthetic designs, especially developed by patient demands, may be associated with increased wearing time.

The satisfaction with the prosthesis has a considerable effect on wearing time $(9,18,19)$. The results from a previous study indicated that most amputees were satisfied with their upper and lower extremity prosthetic devices (9). In another study, $43 \%$ of the amputees reported satisfaction with a lower extremity prosthesis (18). Mohd et al. reported $16.7 \%$ and $8.3 \%$ of the patients were dissatisfied and somewhat dissatisfied with their prostheses (20). Most amputees appeared to be satisfied with the overall performance of their prosthesis in the current study and only $6.7 \%$ of the patients were not satisfied with their prosthesis. It could be commented that overall satisfaction of the patients with lower limb prosthesis was good.

Patients with combat related traumatic amputation face a dramatic change in lifestyle that disturbs all parts of their daily life, including mobility, functional independence, body image, and psychosocial readjustment. These amputees are at risk for compromised quality of life after amputation. Demiral et al. investigated the mean scores for all eight subscales of the SF-36 among the normal population in Turkey (13). Participants in the current study reported worse health indicators compared to the norm that represents the general population in Turkey on several health domains with the biggest differences observed on physical role. Similarly, Allami et al. reported that war veterans with amputation had lower SF-36 scores than general Iranian population norms (21). Talbot et al. found that, both physical and mental scores of the SF-36 in patients with combat related amputations were different from age norms (22). There have been reported some factors that may be associated with quality of life $(23,24)$. Dajpratham et al. reported that higher education, to be employed after amputation, and good prosthetic wearing comfort were associated with the good health related quality of life (23). Asano et al. found that prosthetic mobility, symptoms of depression, social support, comorbidities, daily social activity, prosthetic problems, and age were related with quality of life in patients with amputation (24). It is important to take the associated factors into account because they probably will affect health related quality of life positively.
There are several limitations to the study. First, the study design is cross-sectional in nature, so conclusions are limited. Second, the sample is not representative of the population of persons with amputation in Turkey, since study center commonly serves for veterans and military personnel. Third, the present study was limited in size. Finally, the study lacks a control group.

\section{Conclusion}

War injured amputees are at risk for disturbed quality of life. The cosmetic anxiety was significantly correlated with the daily prosthesis wearing time. Itching, pain and wound were significantly correlated with the prosthesis satisfaction. Despite the limitations, the results of the current study can be helpful in the development of future prostheses. There is a need to conduct large scale multi-center or population based longitudinal studies to assess amputation related factors which affect quality of life in combat related lower limb amputees in Turkey.

\section{Acknowledgments}

Author contributions: Concept; Y.D. and N.M.Ö.A., design; K.A, supervision; E.Y. and Ü.G., resource; Y.D., N.M.Ö.A, K.A. and Ü.G, materials; N.M.Ö.A, data collection \&/or processing; Y.D and Ü.G., analysis \&/or interpretation; Y.D and N.M.Ö.A, literature search; K.A and E.Y., writing; Y.A., N.M.Ö.A, K.A., Ü.G and E.Y., critical review; K.A., Ü.G. and E.Y. No financial support was received from any source for this work.

\section{Conflict of interest}

There are not any funding or grants or equipment provided for the project from any source, financial benefits to the authors, and it is not published in any form of presentation previously.

\section{References}

1. Johannesson A, Larsson GU, Ramstrand N, Turkiewicz A, Wiréhn AB, Atroshi I. Incidence of lower-limb amputation in the diabetic and nondiabetic general population: a 10-year population-based cohort study of initial unilateral and contralateral amputations and reamputations. Diabetes Care. 2009;32(2):275-280.

2. Yaşar E, Tok F, Kesikburun S, et al. Epidemiologic data of trauma-related lower limb amputees: A single center 10-year experience. Injury. 2017;48(2):349-352.

3. Ziegler-Graham K, MacKenzie EJ, Ephraim PL, Travison TG, Brookmeyer R. Estimating the prevalence of limb loss in the United States: 2005 to 2050 . Arch Phys Med Rehabil. 2008;89(1):422-429.

4. Dillingham TR, Pezzin LE, Mackenzie EJ. Limb amputation and limb deficiency: epidemiology and recent trends in the United States. South Med J. 2002;95(8):875-883.

5. Eskelinen E, Lepäntalo M, Hietala EM, et al. Lower limb amputations in southern Finland in 2000 and trends up to 2001. Eur J Vasc Endovasc Surg. 2004;27(2):193-200.

6. Jensen PS, Petersen J, Kirketerp-Møller K, Poulsen I, Andersen $\mathrm{O}$. Progression of disease preceding lower extremity amputation in Denmark: a longitudinal registry study of diagnoses, use of medication and healthcare services 14 years prior to amputation. BMJ Open. 2017;7(11):e016030.

7. Asadollahi R, Saghafinia M, Nafissi N, Montazeri A, 
Asadollahi M, Khatami M. Anxiety, depression and health-related quality of life in those injured by landmines, Ilam, Islamic Republic of Iran. East Mediterr Health J. 2010;16(11):1108-1114.

8. Surrency AB, Graitcer PL, Henderson AK. Key factors for civilian injuries and deaths from exploding landmines and ordnance. Inj Prev. 2007;13(3):197-201.

9. Pezzin LE, Dillingham TR, Mackenzie EJ, Ephraim P, Rossbach P. Use and satisfaction with prosthetic limb devices and related services. Arch Phys Med Rehabil. 2004;85(5):723-729.

10. Murray CD, Forshaw MJ. The experience of amputation and prosthesis use for adults: a metasynthesis. Disabil Rehabil. 2013;35(14):1133-1142.

11. Hawkins AT, Henry AJ, Crandell DM, Nguyen LL. A systematic review of functional and quality of life assessment after major lower extremity amputation. Ann Vasc Surg. 2014;28(3):763-780.

12. Çelik $D$, Çoban Ö. Short Form Health Survey version-2.0 Turkish (SF-36v2) is an efficient outcome parameter in musculoskeletal research. Acta Orthop Traumatol Turc. 2016;50(5):558-561.

13. Demiral $Y$, Ergor G, Unal B, et al. Normative data and discriminative properties of short form 36 (SF-36) in Turkish urban population. BMC Public Health. 2006;6(1):247255.

14. Van de Weg FB, Van der Windt DA. A questionnaire survey of the effect of different interface types on patient satisfaction and perceived problems among trans-tibial amputees. Prosthet Orthot Int. 2005;29(3):231-239.

15. Dillingham TR, Pezzin LE, MacKenzie EJ, Burgess AR. Use and satisfaction with prosthetic devices among persons with trauma-related amputations: a long-term outcome study. Am J Phys Med Rehabil. 2001;80(8):563571.

16. Pezzin LE, Dillingham TR, MacKenzie EJ. Rehabilitation and the long-term outcomes of persons with trauma-related amputations. Arch Phys Med Rehabil. 2000;81(3):292-300.

17. Gailey R, McFarland LV, Cooper RA, et al. Unilateral lower-limb loss: prosthetic device use and functional outcomes in service members from Vietnam war and OIF/ OEF conflicts. J Rehabil Res Dev. 2010;47(4):317-331.

18. Gauthier-Gagnon C, Grisé MC, Potvin D. Enabling factors related to prosthetic use by people with transtibial and transfemoral amputation. Arch Phys Med Rehabil. 1999;80(1):706-713.

19. Biddiss E, Chau T. Upper-limb prosthetics: Critical factors in device abandonment. Am J Phys Med Rehabil. 2007;86(1):977-987.

20. Mohd Hawari N, Jawaid M, Md Tahir P, Azmeer RA. Case study: survey of patient satisfaction with prosthesis quality and design among below-knee prosthetic leg socket users. Disabil Rehabil Assist Technol. 2017;12(8):868874.

21. Allami M, Yavari A, Karimi A, Masoumi M, Soroush M,
Faraji E. Health-related quality of life and the ability to perform activities of daily living: a cross-sectional study on 1079 war veterans with ankle-foot disorders. Mil Med Res. 2017;4(1):37-41.

22. Talbot LA, Brede E, Metter EJ. Psychological and Physical Health in Military Amputees During Rehabilitation: Secondary Analysis of a Randomized Controlled Trial. Mil Med. 2017;182(5):e1619-e1624.

23. Dajpratham $P$, Tantiniramai $S$, Lukkanapichonchut $P$. Health related quality of life among the Thai people with unilateral lower limb amputation. J Med Assoc Thai. 2011;94(2):250-255.

24. Asano M, Rushton P, Miller WC, Deathe BA. Predictors of quality of life among individuals who have a lower limb amputation. Prosthet Orthot Int. 2008;32(2):231-243. 